\title{
Endemicity and Community Composition of Marine Species along the NW Pacific and Adjacent Arctic
}

\section{Ocean}

\author{
Hanieh Saeedi ${ }^{\ddagger, \S, l}$, Marianna Simoes ${ }^{\ddagger, \S}$, Angelika Brandt ${ }^{\ddagger}, \S$ \\ ‡ Senckenberg Research Institute and Natural History Museum; Department of Marine Zoology, Frankfurt am Main, Germany \\ $\S$ Goethe University Frankfurt, Institute for Ecology, Diversity and Evolution, Frankfurt am Main, Germany \\ I OBIS data manager, deep-sea node, Frankfurt am Main, Germany
}

Corresponding author: Hanieh Saeedi (hanieh.saeedi@gmail.com)

Received: 03 Jun 2019 | Published: 18 Jun 2019

Citation: Saeedi H, Simoes M, Brandt A (2019) Endemicity and Community Composition of Marine Species along the NW Pacific and Adjacent Arctic Ocean. Biodiversity Information Science and Standards 3: e36750.

https://doi.org/10.3897/biss.3.36750

\begin{abstract}
The Northwestern (NW) Pacific Ocean lies in one of the most productive, speciose, and diverse regions of the World Ocean, and includes several shallow-water oceanic islands and deep-sea basins of varying depth, hydrology, and degree of isolation. The adjacent Arctic Ocean areas include the northern Bering and southern Chukchi Seas of the Arctic Ocean with short food chains and shallow depths characterizing high productivity areas. Despite its magnitude and relevance, characterization of species diversity and community composition patterns in the NW Pacific Ocean remains poorly explored and largely unknown. Here we attempt to discover how geographic boundaries and depth shape current community assemblages and delimit species distribution ranges and richness using open access data. We also show how endemicity and community composition vary between tropical and temperate NW Pacific and the adjacent Arctic Ocean considering sampling bias. The Eastern Philippine Sea was the hotspot of species richness in the NW Pacific and its adjacent Arctic Ocean even when accounting for sampling bias. The lowest species richness was observed in Papau. Despite high species richness in the Eastern Philippine Sea, the Yellow Sea and Gulf of Tonkin had the highest endemicity rates (ca. 60\%) among all other ecoregions. Endemicity ranged $20-40 \%$ across
\end{abstract}


19 ecoregions. Chordata, Arthropoda, and Mollusca contributed more than $50 \%$ to the total community composition in the NW Pacific where as Arthropoda, Annelida, and Mollusca were the dominant taxa shaping ca. $82 \%$ of the Arctic Ocean community. Pelagic species richness was higher than the benthic one in both shallow-water and deep-sea regions of the NW Pacific Ocean. However, in the shallow and deep Arctic Ocean, most of the taxa were benthic excluding the deep Kara Sea where pelagic deep-sea species dominated the whole community. Two significantly distinctive clusters (North and South clusters) were classified based on species richness similarity analysis in this area including ecoregions of the (1) Arctic Ocean and North NW Pacific, and (2) Mid to South NW Pacific.

\section{Keywords}

species richness, endemicity, community composition, NW Pacific, Arctic Ocean, sampling effort, cluster analysis.

\section{Presenting author}

Hanieh Saeedi

\section{Presented at}

Biodiversity_Next 2019

\section{Acknowledgements}

This paper was part of the "Biogeography of the NW Pacific deep-sea fauna and their possible future invasions into the Arctic Ocean project (Beneficial project)". Beneficial project (grant number 03F0780A) was funded by Federal Ministry for Education and Research (BMBF: Bundesministerium für Bildung und Forschung) in Germany. We would like also to thank the JQ Young Academy at Goethe University for funding the conference attendance.

\section{Funding program}

Beneficial project (grant number 03F0780A) was funded by the Federal Ministry for Education and Research (BMBF: Bundesministerium für Bildung und Forschung) in Germany. JQ Young Academy at Goethe University funded the conference attendance. 


\section{Hosting institution}

Senckenberg Research Institute and Natural History Museum and Goethe University Frankfurt, Frankfurt am Main, Germany 